\title{
Nonsurgical Removal of Knotted Pulmonary Artery Catheter
}

\author{
Mark M. Smith ${ }^{\mathrm{a}}$, David W. Barbara ${ }^{\mathrm{a}, \mathrm{b}}$, Laurence C. Torsher ${ }^{\mathrm{a}}$, Christopher J. Jankowski ${ }^{\mathrm{a}}$
}

\begin{abstract}
Though controversy exists regarding the utility of pulmonary artery catheters (PAC), their use persists in select patients. Knotting of these catheters upon insertion is a rare but serious complication. We present 2 cases of coagulopathic patients undergoing orthotopic liver transplantation complicated by PAC knotting on attempted line placement. Both knotted PAC were successfully removed nonsurgically in the operating room, allowing for timely continuation of the planned transplantations. It is essential for the clinician to recognize knotted PAC and understand strategies for safe removal.
\end{abstract}

Keywords: Pulmonary artery catheter; Knot; Complications; Liver transplantation

\section{Introduction}

Clinical use of pulmonary artery catheters (PAC) dates to the early 1970's [1]. Due to controversy regarding the utility of PAC, widespread use has declined in recent years [2, 3]. PAC use however can still be found in select patients, including those undergoing orthotopic liver transplantation [4]. Clinicians utilizing PAC must recognize potential complications and understand treatment options. We present 2 patients who underwent orthotopic liver transplantation (OLT) complicated by PAC knotting.

Manuscript accepted for publication November 16, 2012

${ }^{\mathrm{a} D e p a r t m e n t ~ o f ~ A n e s t h e s i o l o g y, ~ M a y o ~ C l i n i c ~ C o l l e g e ~ o f ~ M e d i c i n e, ~}$ Rochester, Minnesota, USA

${ }^{\mathrm{b}}$ Corresponding author: David W. Barbara, Department of Anesthesiology, Mayo Clinic College of Medicine, 200 First ST SW, Rochester, MN 55905, USA. E-mail: Barbara.David@mayo.edu

doi: http://dx.doi.org/10.4021/jmc1016e

\section{Case Report}

Two males, ages 41 and 63 years, presented for combined liver and kidney transplant and OLT, respectively. Both patients had abnormal preoperative coagulation laboratory studies (Table 1). Anesthesia was induced and intubation performed uneventfully in both cases.

In each patient, a 9 French double lumen central venous introducer was placed in the right internal jugular vein utilizing dynamic ultrasound guidance with good visualization of anatomy. Multiple attempts at placement of an 8 French oximetric pulmonary artery catheter were unsuccessful. Upon attempted removal of the PAC, resistance was met at roughly $25 \mathrm{~cm}$ in each case. Intraoperative fluoroscopy was performed, revealing a knot in the distal PAC (Fig. 1). Repeated attempts to unravel the catheter by passing a pacing wire down the distal port of the PAC were unsuccessful. Given the projected delay for interventional radiology assistance that would have resulted in increasing donor organ ischemic time, percutaneous removal was performed in both cases.

Under fluoroscopic guidance, traction was applied to the PAC and the knot size was reduced against the introducer. A guide wire was passed down the distal lumen of the introducer, exiting the same lumen as the PAC, thereby bypassing the knot. Next, the introducer and PAC were removed with traction en bloc (Fig. 2) with the guidewire left in the IJV. A new introducer was placed over the guidewire and a new PAC inserted without complication on the first attempt. Location of the new introducer and PAC were fluoroscopically confirmed. Both patients then underwent transplantation without complications and experienced uneventful postoperative courses.

\section{Discussion}

Complications related to PAC use have been reported in up to $24 \%$ of cases; however, PAC knot formation is exceedingly rare [5]. Of the intravascular catheters used today, PAC account for $64-67 \%$ of knotted devices [6]. Although significant controversy exists regarding use of PAC in surgical and 


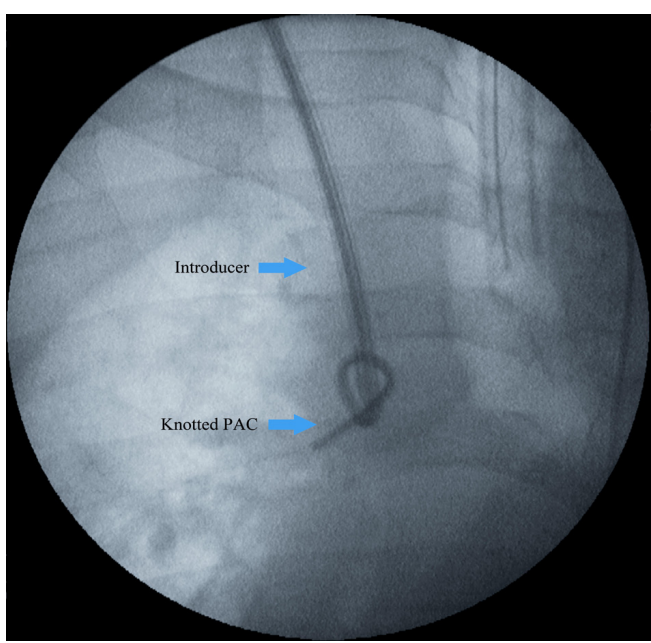

Figure 1. Fluoroscopy demonstrating knotted pulmonary artery catheter (PAC). The introducer sheath abuts the loose knot prior to applying traction to the PAC to reduce the knot size against the introducer.

nonsurgical patients, it is important for the clinician to understand their potential complications.

Knotting of PAC is thought to occur when passage into the pulmonary artery is unsuccessful and looping occurs within the right ventricle [7]. This looping over of the PAC may be due to insertion of an excessive length of the PAC [7]. Inability to obtain a wedge pressure should prompt retraction to $30 \mathrm{~cm}$ and reattempt flotation into the pulmonary artery [7]. After multiple unsuccessful attempts, providers will often completely retract and reinsert the PAC. If resistance to retraction is encountered, there should be a concern for knotting of the catheter, or entanglement around cardiac chordae or valves. The distance at which resistance is encountered may help differentiate between these complications, with the former occurring when resistance is met at lesser distances of PAC insertion, as encountered in our cases. Fluoroscopic

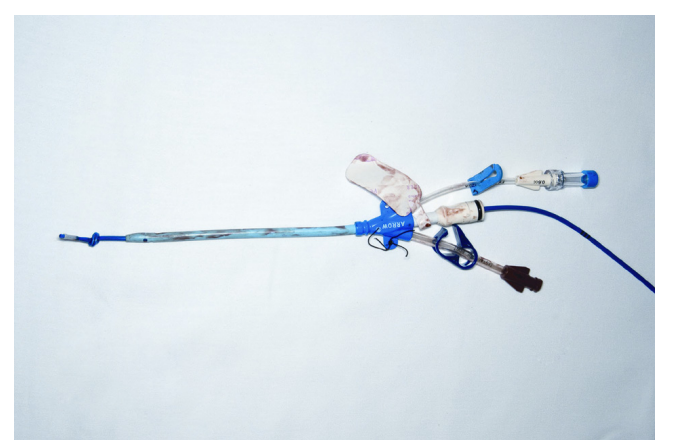

Figure 2. Knotted pulmonary artery catheter (PAC) after removal. The knotted PAC was removed by applying traction to the PAC, thereby reducing the knot size against the introducer. The PAC and introducer were then removed en bloc. 
evaluation can also assist with diagnosis and PAC knot location as noted in our cases.

Several strategies for both surgical and nonsurgical knotted PAC removal have been described [6-9]. Insertion of a core-guided wire through the PAC under fluoroscopy is often a first step in attempt to unravel the knotted catheter [6-10]. Utilization of a pacer wire is another option and was unsuccessfully employed in both of our cases. Unsuccessful attempts at un-knotting the catheter prompt consideration of alternative removal techniques. One technique involves ligating the PAC and replacing the initial introducer with a larger introducer over the ligated PAC. With this technique the knot is contained within the lumen of the larger introducer, after which both the knotted catheter and introducer are removed simultaneously $[6,8]$. Assistance of interventional radiology may be utilized, but may be difficult to arrange in a timely fashion, especially given the after-hours nature of many liver transplantations. Interventional radiology techniques include the use of a retrieval basket, pigtail catheter, loop snare, or endomyocardial biopsy forceps inserted through an alternate venous access site to secure and remove the knotted catheter which is ligated and pulled through the introducer [6-9]. The retrieval device is then retracted and a small skin incision is made to remove the knotted catheter, or, for larger knots, a venous cutdown is performed [6-9]. Primary surgical removal performing a cutdown and venotomy at the initial insertion site has also been described [7-9]. For large and complex knots, surgical removal is often the only option and is performed via cutdown or open procedures, occasionally requiring cardiopulmonary bypass $[6-9,11]$.

Patients undergoing orthotopic liver transplantation (OLT) present additional challenges such as coagulopathy and significant time constraints, making traditional and potentially more time-consuming knotted PAC removal techniques less ideal. The after-hours timing of both liver transplantations coupled with the need to reduce donor organ ischemic time limited available options compared with elective surgical patients. The percutaneous technique used in our case report carries a theoretical risk of complications such as venous laceration and uncontrolled bleeding upon removal of the knotted catheter [7-9]. We decided this risk was mitigated by the ability to insert a new introducer through the original puncture site into the internal jugular vein by maintaining patency with a guidewire. Intraoperative fluoroscopy demonstrated the knot diameter after retraction against the introducer was not significantly larger than that of the introducer diameter.
In conclusion, PAC knot formation is a rare, yet potentially serious, complication. Clinicians caring for patients with such devices must be able to recognize this complication and tailor treatment strategies to each individual patient.

\section{References}

1. Swan HJ, Ganz W, Forrester J, Marcus H, Diamond G, Chonette D. Catheterization of the heart in man with use of a flow-directed balloon-tipped catheter. N Engl J Med. 1970;283(9):447-451.

2. Connors AF, Jr., Speroff T, Dawson NV, Thomas C, Harrell FE, Jr., Wagner D, Desbiens N, et al. The effectiveness of right heart catheterization in the initial care of critically ill patients. SUPPORT Investigators. JAMA. 1996;276(11):889-897.

3. Sandham JD, Hull RD, Brant RF, Knox L, Pineo GF, Doig CJ, Laporta DP, et al. A randomized, controlled trial of the use of pulmonary-artery catheters in highrisk surgical patients. N Engl J Med. 2003;348(1):5-14.

4. Steadman RH. Anesthesia for liver transplant surgery. Anesthesiol Clin North America. 2004;22(4):687-711.

5. Boyd KD, Thomas SJ, Gold J, Boyd AD. A prospective study of complications of pulmonary artery catheterizations in 500 consecutive patients. Chest. 1983;84(3):245249.

6. Katsikis A, Karavolias G, Voudris V. Transfemoral percutaneous removal of a knotted Swan-Ganz catheter. Catheter Cardiovasc Interv. 2009;74(5):802-804.

7. Lopes MC, de Cleva R, Zilberstein B, Gama-Rodrigues JJ. Pulmonary artery catheter complications: report on a case of a knot accident and literature review. Rev Hosp Clin Fac Med Sao Paulo. 2004;59(2):77-85.

8. Karanikas ID, Polychronidis A, Vrachatis A, Arvanitis DP, Simopoulos CE, Lazarides MK. Removal of knotted intravascular devices. Case report and review of the literature. Eur J Vasc Endovasc Surg. 2002;23(3):189-194.

9. Georghiou GP, Vidne BA, Raanani E. Knotting of a pulmonary artery catheter in the superior vena cava: surgical removal and a word of caution. Heart. 2004;90(5):e28.

10. Mond HG, Clark DW, Nesbitt SJ, Schlant RC. A technique for unknotting an intracardiac flow-directed balloon catheter. Chest. 1975;67(6):731-733.

11. Bagul NB, Menon NJ, Pathak R, Platts A, Hamilton G. Knot in the cava--an unusual complication of swan-ganz catheters. Eur J Vasc Endovasc Surg. 2005;29(6):651653. 